\title{
Associations between behaviours that challenge in adults with intellectual disability, parental perceptions, and parental mental health
}

\author{
Waite, J., Rose, J., Wilde, L., Eden, K., Stinton, C., \\ Moss, J. \& Oliver, C.
}

Cerebra Centre for Neurodevelopmental Disorders, School of Psychology, University of Birmingham

Please use this reference when citing this work: Waite, J., Rose, J., Wilde, L., Eden, K., Stinton, C., Moss, J. \& Oliver, C. (2017). Associations between challenging behaviour in adults with intellectual disability, parental perceptions, and parental mental health. British Journal of Clinical Psychology 


\begin{abstract}
Objectives. This study examined parental perceptions of behaviours that challenge (CB) in their adult children with intellectual disability (ID), and explored whether perceptions mediated associations between CB and parental psychological distress. Design. A withingroup correlational design was employed.
\end{abstract}

Methods. Sixty-five parents reported on individuals with genetic syndromes and ID who had chronic behaviours that challenge (CB). Parents completed the Illness Perception Questionnaire-Revised (IPQ-R) adapted to measure perceptions of self-injury, aggression or property destruction, alongside assessments of parental locus of control, attributions about behaviour, parental psychological distress, and CB.

Results. A high proportion of parents evidenced anxiety and depression at clinically significant levels (56.9\% and 30.8\%, respectively). Contrary to predictions, psychological distress was not significantly associated with $\mathrm{CB}$. The perception that the adult with ID exerted control over the parent's life mediated the association between $\mathrm{CB}$ and parental psychological distress. Few parents endorsed operant reinforcement as a cause of CB (< $10 \%)$.

Conclusions. The high levels of psychological distress in parents is notable and of concern. Further research should consider the reasons why parents have causal attributions that might be inconsistent with contemporary interventions.

Key words: Adults; parents; attributions; self-regulatory model; challenging behaviour; intellectual disability. 


\section{Practitioner Points}

- Parents experience high levels of psychological distress while supporting adults with ID who engage in chronic behaviours that challenge.

- Parental Locus of Control about CB was most strongly associated with parental psychological distress rather than the degree of $\mathrm{CB}$ exhibited by the individual with ID.

- Few parents endorsed operant reinforcement as a cause of behaviours that challenge. 


\section{Associations between challenging behaviour in adults with intellectual disability, parental perceptions, and parental mental health}

Approximately $60 \%$ of individuals with intellectual disability (ID) live at home with their parents once they reach adulthood (Department of Health, 2001), and an estimated 10-15\% of adults with ID engage in behaviours that challenge. Aggression, property destruction, and self-injurious behaviour are amongst the most prevalent behaviours that challenge with a robust evidence base for intervention (Emerson et al., 2001). These behaviours are more likely to occur in individuals with a diagnosis of a specific genetic syndrome with associated ID (45-93\% for self-injury and 40-74\% for aggression; Arron, Oliver, Moss, Berg \& Burbidge, 2011). Hence, the behaviour of this high-risk adult population warrants investigation alongside examination of parental involvement.

Self-injury, aggression and property destruction are associated with poorer parental wellbeing, evidenced by elevated prevalence of anxiety and depression (Hastings, 2002; Hodapp, Fidler \& Smith, 1998; Eisenhower, Baker \& Blacher, 2005, Beck, Hastings, Daley \& Stevenson, 2004; Totsika, Hastings, Emerson, Berridge, \& Lancaster 2011). The nature of this association is still being defined and the majority of research has been conducted with families of children with ID, as opposed to adults. Hill and Rose (2010) argue that it is frequently assumed that the challenges parents experience when supporting a person with ID are unchanged across the life span. However, because behaviours that challenge persist in a high proportion of individuals with ID (Murphy et al., 2005; Taylor et al., 2011), it is possible that continued exposure to chronic behavioural difficulties impacts cumulatively on parents over time. Furthermore, parents who have poorer mental health may adopt parenting practises 
that potentially contribute to the maintenance or escalation of challenging behaviour $(\mathrm{Xu}$, Neece, \& Parker, 2014).

Whilst there is an association between behaviours that challenge and well-being, variability in outcomes for parents indicates that other factors, such as social support, child characteristics and parental perceptions/cognitions, are influential and warrant attention (MacDonald Hastings \& Fitzsimons., 2010; McClintock, Hall \& Oliver, 2003; Plant \& Sanders, 2007). In particular, research into the nature of parental perceptions has increased steadily with a focus on causal attributions, self-efficacy, psychological acceptance and locus of control (Dagnan, Grant \& McDonnell, 2004; Hassall, Rose \& McDonald, 2005; Hastings \& Brown, 2002; MacDonald et al., 2010; Jones et al., 2014). The association between parental perceptions and parental outcomes is complex but clearly important. For example, in a longitudinal study with parents of children with ID, parental locus of control was associated with well-being but did not moderate the association between well-being and behaviours that challenge (Lloyd \& Hastings, 2009). In addition, there is evidence that selfefficacy may mediate, and that parental criticism may moderate, the association between behaviours that challenge and parent well-being (Hastings \& Brown, 2002; Lancaster, Balling, Hastings \& Lloyd, 2014).

While previous research has indicated that there are a number of parental cognitive variables that could influence the association between parental well-being and behaviours that challenge, a unifying model that integrates the relevant constructs has rarely been applied. Models from the health psychology literature may be applicable and could extend understanding of parental perceptions of behaviours that challenge in adults with ID who live at home, and aid exploration of associations between perceptions and parental well-being. 
Leventhal's Self-Regulatory Model was developed initially as a framework for understanding how people construct representations of illness and has been applied in related fields (Leventhal et al., 1997; Leventhal, Nerenz \& Steele, 1984). The model has utility when exploring perceptions of residential staff working with adults who show behaviours that challenge, carers who support individuals with schizophrenia, and it has been used to explore parents' perceptions of Autism Spectrum Disorder (Al Anbar, Dardennes, Prado-Netto, Kaye \& Contejean, 2010; Barrowclough, Lobban, Hatton \& Quine, 2001; Mills \& Rose, 2011; Williams \& Rose, 2007). A key advantage of this model is it encompasses a wide range of cognitive variables, and the inter-correlations between these variables are highly consistent across a wide range of populations and difficulties (Hagger \& Orbell, 2003). If this model is applicable to the group of interest in this study, then the implications from other studies may be readily generalised.

Leventhal proposed that individuals form representation schemas about the identity, timeline, consequences, control over, and cause of an illness ('illness' hereafter called 'adversity'). These schemas are influenced by three levels of information: 1) cultural and societal norms about the adversity, 2) information from professionals and significant others and 3) information from personal experience of the adversity. These representation schemas are most commonly measured by the Illness Perception Questionnaire-Revised (IPQ-R; MossMorris, Petrie \& Weinman. 2002), which evaluates the five schemas originally described by Leventhal, plus an additional three that were added later: cyclical timeline, illness coherence and emotional representations (Moss-Morris et al., 2002).

The IPQ-R subscale that measures perceptions about the cause of an adversity (cause scale) is usually developed specifically for the adversity under investigation. Causal factors associated 
with representations of illnesses/adversities usually fall into four domains: biological, emotional, psychological and environmental (Hagger \& Orbell, 2003). These domains overlap with a biopsychosocial approach to understanding behaviours that challenge. Research on parental perceptions of the causes of behaviours that challenge has indicated that parents/carers often endorse internal emotional or internal organic causes, such as a person's mood, while attributing less importance to how behaviour is shaped through the social environment via operant reinforcement (Oliver, Hall, Hales \& Head., 1996). Further research into parents' perceptions of the causes of behaviour in their adult children is warranted, particularly as internal perceptions of cause may be associated with parental psychological distress (Hastings \& Brown, 2002).

A primary aim of the study was to document levels psychological distress, evidenced by the presence of anxiety and depression, experienced by parents of adults with ID who engage in chronic behaviours that challenge. A further primary aim was to explore whether greater psychological distress is associated with higher scores on a measure of behaviours that challenge, as would be predicted based on previous literature, and to examine whether parental cognitive variables mediate this association. The secondary aim of this research was to develop a new cause scale for the IPQ-R and collect preliminary data on parents' perceptions of the causes of behaviours that challenge.

It was predicted that higher challenging behaviour scores would be associated with greater levels of parental psychological distress (anxiety and depression). It was also predicted that parents who perceived the behaviour to be less controllable and more chronic would experience greater levels of distress, and that these perceptions may mediate the association between behaviours that challenge and parental well-being. 


\section{Methods}

\section{Recruitment}

Participants were recruited from an existing sample of 313 individuals who had completed questionnaires about their adult child 8 months prior to this study, as part of a longitudinal study exploring behaviour and cognition in genetic syndromes associated with ID. Participants were originally recruited for the longitudinal questionnaire study via the UK syndrome support groups including the Angelman Syndrome Support, Education and Research Trust (ASSERT), Cornelia de Lange Foundation UK and Ireland, Cri Du Chat Support Group, Lowe Syndrome Trust, Prader-Willi Association, Smith-Magenis Foundation, and Fragile-X Association.

Inclusion criteria were that the person with ID was aged 16 years or over, lived at home with their parent/caregiver, and had been identified as engaging in aggression, self-injury, or destruction of property at the most recent follow-up conducted in 2011 and at least one previous time point. Of the 313 individuals, 131 parents of children with Angelman $(\mathrm{AS}: N=21)$, Cornelia de Lange (CdLS: $N=34)$, Cri du Chat $(\mathrm{CdC}: N=4)$, Lowe (LS: $N=14$ ), Prader-Willi (PWS: $N=12$ ), Smith Magenis (SMS: $N=11$ ), and Fragile-X (FXS: $N=35$ ) syndromes met inclusion criteria. Invitation letters were sent to these parents, and 77 parents participated (CdC: $N=3,75 \%$; AS: $N=14,66.68 \%$; CdLS: $N=18,52.9 \%$; FXS: $N=19,54.3 \%$; PWS: $N=8,66.7 \% ;$ LS: $N=9$, 64.3\%; SMS: $N=6,54.6 \%)$. Three participants were excluded because their child had moved into residential accommodation in the last 12 months. An additional nine participants were excluded because more than one child with a diagnosis of a genetic syndrome lived in the household. 


\section{Participants}

The final sample consisted of 65 parents (mean age: 52.05 years; range $=34.00-76.00$ ); 62 were mothers $(95.4 \%)$. These were parents of children with AS $(N=13), \mathrm{CdC}(N=2), \mathrm{CdLS}$ $(N=18), \operatorname{LS}(N=9)$, PWS $(N=6), \operatorname{SMS}(N=5)$, FXS $(N=12)$. The mean age of the adults with ID was 26.34 years (range: 16.84-51.93); 53.8\% were male. Approximately one-third (36.9\%) of adults with ID had been diagnosed by a paediatrician, $50.8 \%$ by a clinical geneticist, $10.8 \%$ by a GP, and $1.5 \%$ by another professional. Demographic variables from the Wessex Questionnaire (Kushlick, Blunden, \& Cox, 1973) for the adults with ID $(N=63$ 65 across subscales) indicated that $64.6 \%$ were mobile, $64.1 \%$ had normal vision, $81 \%$ had normal hearing, and $68.8 \%$ were partially verbal or verbal. Approximately half of the sample (55.4\%) were partially able/able, which is defined on the Wessex Questionnaire as showing some independence in feeding, dressing, and washing, although the person may require support with these activities.

\section{Procedure}

Invitation letters offered participation in an online questionnaire study exploring parents' perceptions of behaviours that challenge. Twenty-two participants $(33.8 \%)$ requested a paper copy. Four to 6 weeks after sending invitation letters, parents were contacted via telephone to enquire whether they had questions or difficulties accessing the survey.

Participants completed the Challenging Behaviour Questionnaire first because following this they indicated which of the behaviours measured by this questionnaire (self-injury, aggression, or property destruction) had the greatest impact on their day-to-day life so that this behaviour could be used as a focus when the IPQ-R was completed. Participants then completed the remaining measures. 


\section{Measures.}

The CB Questionnaire: Adapted (CBQ; Hyman, Oliver \& Hall, 2002). This brief, informant-based questionnaire assesses self-injury, physical aggression, and destruction of property with ratings of frequency, severity, and duration on five-point Likert scales. For the frequency rating, parents report on when they would expect to next see the behaviour, ranging from 'by this time next month' to 'in the next 15 min'. For the severity rating, parents report on how often they need to physically intervene to keep their child or others safe, ranging from 'never' to 'at least once an hour', and for duration ratings, answers range from 'less than a minute' to 'more than an hour'. In the original measure, the Likert scales are administered for the self-injury item only; however, in the present study the measure was adapted by replicating these scales for physical aggression and destruction of property. Previous examination of the psychometric properties of the questionnaire with individuals with ID has demonstrated good inter-rater reliability (reliability coefficients range from .75 to .92; Hyman et al., 2002).

Modified Illness Perception Questionnaire-Revised (IPQ-R; Moss-Morris et al., 2002). The Illness Perception Questionnaire captures the components of Leventhal's Self-Regulatory Model of Illness Behaviour (Leventhal et al., 1984). The subscales are the following: identity, timeline (acute/chronic), timeline (cyclical), consequences, personal control, treatment control, illness coherence, emotional representations, and cause. For all subscales, apart from the identity and cause scale, informants use a 5-point Likert scale that ranges from strongly disagree to strongly agree. The measure has shown good predictive validity, for example, adjustment to illness in multiple sclerosis (Moss-Morris et al., 2002). The subscales 
of the Illness Perception Questionnaire-Revised have good internal reliability (range .75-.89) and acceptable test-retest reliability (range .46-.88; 75\% > .70; Moss-Morriset al., 2002).

The subscales with Likert scales were adapted to measure parents' views of CB. Items were modified by changing the word 'illness' to a topography of $\mathrm{CB}$ (e.g., aggression) in agreement with guidance for using the IPQ-R (www.uib.no/ipq/accessed 06.03.12). The topography of CB substituted for the word 'illness' was determined by the question that asked parents to indicate the behaviour that had the most impact on their day-to-day lives. Slight modifications were made to the wording to make items applicable and transparent to parents (e.g., the word 'my' was changed to 'his/her', the first three questions were prefaced with 'looking ahead to the future'). Overall, there were 38 items. The identity subscale was omitted because this scale typically includes a list of symptoms that form part of an illness. The emotional representations subscale was removed because of concern that the items were too similar to items from the outcome measure of parental depression and anxiety.

The new cause scale developed for this study captured the four causal domains described in health psychology literature: biological, emotional, psychological, and environmental (Hagger \& Orbell, 2003), and was informed by research that carers often endorse internal factors (e.g., biological or emotional) for $\mathrm{CB}$ over external factors such as reinforcement contingencies (Oliver et al., 1996). Parents indicated whether they agreed that that aggression, self-injury, or property destruction was caused by the following: the person's syndrome, atypical brain development, poor mental health, mood/emotions, the situation/environment around the person, learning/reinforcement, and pain (see Appendix A) (Beail, 2003; Breau, Camfield, McGrath, \& Finley, 2003; Esbensen, 2011; Iwata, Dorsey, Slifer, Bauman, \& Richman, 1994; McGill \& Langthorne, 2011; Oliver, Sloneem, Hall, \& 
Arron, 2009). There were two items per cause that were rated on a five-point Likert scale (strongly disagree to strongly agree).

The two items per cause were combined in the following way: If participants agreed with each item, they were assigned a score of five; if they agreed with one and partially agreed with another, they were assigned a score of four; if they partially agreed with both or agreed and disagreed, they were assigned a score of three; if the partially agreed and disagreed, they were assigned a score of two; and if they disagreed with both items, they were assigned a score of one. The 5-point scale was used in analyses. Higher scores on the personal control, treatment control and illness coherence subscales represent more strongly held positive beliefs, whereas higher scores on the timeline and consequences subscales represent more strongly held negative beliefs.

Controllability Beliefs Scale (CBS; Dagnan, Grant, McDonnell, 2004). The Controllability Beliefs Scale was originally designed to measure staff attributions concerning dementia service users' CB. However, items are applicable to individuals with ID. Informants use a 5-point scale to indicate agreement with statements concerning the reasons why $\mathrm{CB}$ occurs. The scale has good internal reliability $(\alpha=.89)$. It has been employed in studies with staff teams which support service users with ID (Dilworth, Phillips, \& Rose, 2011; Kalsy, Heath, Adams, \& Oliver, 2007; Mills \& Rose, 2011). A higher score signifies that the informant believes the person with ID has greater internal control over CB. 


\section{Parental Locus of Control Scale (short-form revised) (PLOC-SFR; Hassall, Rose, McDonald, 2005).}

The Parental Locus of Control Scale (short form revised) is a 24-item questionnaire. Informants respond to statements on five-point Likert scales (disagree to agree strongly). For the original 47 item scale, internal consistency ranges from .65 to .77 for the subscales and is .92 for the total scale (Campis, Lyman, \& Prentice-Dunn, 1986). Test-retest reliability for the entire scale is 0.83. In this study, a short form of the measure was used (Hassall et al., 2005). Hassall et al. selected the six items with the highest factor loadings on each subscale yielding four subscales: parental efficacy, parental responsibility, parent's control over child, child's control over parent's life; and a total score. A higher score on this measure indicates a greater external locus of control. The PLOC-SFR has been used in studies with individuals with ID (Hassall et al., 2005; Hill \& Rose, 2009).

Hospital Anxiety and Depression Scale (Zigmond \& Snaith, 1983). This is a widely used measure of anxiety and depression (Bjelland, Dahl, Haug, \& Neckelmann, 2002). It has 14 items with four possible responses. Informants rate their experience over the last few days. It yields an anxiety score, a depression score, and a composite anxiety-depression score. The total score has been argued to be a measure of general psychological distress (Johnston, Pollard, \& Hennessey, 2000). Individuals scoring above eight on the anxiety and depression scales are categorized as falling above a clinical cut-off, with scores classified as mild (8-10), moderate (11-14) and severe (14+). The measure has excellent test-retest reliability $(r=.84$ and .85) and internal consistency (Cronbach's alpha: .83 for anxiety and .82 for depression). Studies support the use of the HADS for non-clinical populations (Bjelland et al., 2002). 


\section{Data Analysis}

Calculation of CB scores. Only a small number of participants reported destruction of property, so aggression and destruction of property were combined into one composite score (Agg/Des composite). Self-injurious behaviour was included as a separate variable. A total CB composite was also calculated by combining aggression, self-injury, and property destruction to enable one analysis across all participants as the $N$ was lower for the individual behaviours. To calculate these composites, the scores for frequency, duration, and severity of each behaviour were standardized by conversion into $z$-scores and then these were averaged to yield the CBQ total score. The subscale scores and composite scores were used in the analyses of parental perceptions of CB.

IPQ Subscales and Cause Scale Composite Scores. The IPQ was adapted for this study so prior to further analyses, the internal consistency of each subscale was examined. Cronbach's alpha was good to excellent for five of six subscales $(.81-.93)$. Alpha for the timelinecyclical subscale was adequate (.68) (see Table 1).

Table 1.

Internal consistency of the IPQ-R subscales and Cause Scale

\begin{tabular}{lll}
\hline IPQ Subscales & N & Chronbach's alpha coefficients \\
\hline Timeline Chronic & 65 & .89 \\
Timeline Cyclical & 65 & .68 \\
Consequences & 65 & .83 \\
Personal Control & 65 & .81 \\
Treatment Control & 65 & .82 \\
Illness Coherence & 65 & .93 \\
\hline Newly developed cause scale & & Spearman Brown's coefficients \\
\hline Mental Health & 61 & .78 \\
Brain Development & 61 & .75 \\
Reinforcement & 61 & .76 \\
Situation & 61 & .68 \\
Mood & 62 & .51 \\
Pain & 62 & .86 \\
Syndrome & 62 & .76 \\
Note. N varies due to excluded outliers (max N excluded - 3 per pair) and missing data due to \\
participants missing an item.
\end{tabular}


The items on the newly developed cause scale were inspected, and the two-item scales were inadequately correlated to justify combining the items for each causal factor. However, this was only after three participants scores were omitted because inspection of scatter plots for each pair of items revealed these participants' responses conflicted strongly and systematically on the items across the measure, reflecting a reporting error due to the reverse wording of some items. Spearman Brown's coefficients were calculated, and for six of the seven subscales, these were good (mean: .77; range .68-.86). The mood subscale was removed from the analysis due to a lower Spearman's Brown coefficient (.51). Prior to this, combining the mood with the mental health subscale, and the syndrome with the brain development subscales was considered to reduce the number of subscales; however, Cronbach's alpha for these combinations was poor $(.51 \& .55)$, reducing the internal consistency of the mental health, syndrome, and brain development subscales. Furthermore, while combining the subscales could have reduced the number of comparisons needed, mental health difficulties as captured by the mental health subscale may be distinct from typical daily fluctuations in mood. Likewise, a person's syndrome identity may impact differently on a parent's perceptions of the cause of behaviour than overall developmental delay captured by the brain development subscale.

Data Analysis Strategy. Inspection of normality plots and tests revealed that a proportion of the subscales were not normally distributed so nonparametric correlations, Friedman, Wilcoxon signed ranks, and Mann-Whitney U-tests were employed. Mediation analyses were conducted to explore the role or parental cognitive variables on determining distress associated with CB. Due to the small sample sizes, a bias-corrected bootstrapping method was applied (Preacher \& Hayes,2008), which has been shown to be one of the most powerful mediation methods (Fritz \& MacKinnon, 2007). Unlike traditional causal steps approaches to 
mediation analyses (e.g., Baron \& Kenny, 1986), this approach does not require that a significant main effect be found between the IV and DV prior to the mediation analyses. Rucker, Preacher, Tormala, and Petty (2011) argue that the assumption that a significant main effect must be present before indirect effects can be explored is unnecessarily restrictive and may lead to misleading or false conclusions; therefore, mediation analyses were conducted despite the absence of main effects. In the mediation analyses, if the confidence intervals arising from the bootstrapping analyses do not cross zero, significant mediation has occurred. Due to the exploratory nature of the correlational analyses, all correlations are reported at three levels $.005, .01$, and .05 to aid interpretation; however, due to multiple tests only correlations <.005 are reported as significant. An alpha level of .05 was adopted for the mediation analyses as this was a stand-alone analysis. Post hoc analyses for the cause scalewere conducted using a conservative $p$-value of .005 .

\section{Results}

\section{Descriptive statistics}

Descriptive statistics are displayed in Table 2, and details of the duration, severity, and frequency of the $\mathrm{CB}$ displayed by the adults with ID are displayed in Table 3. The interquartile ranges indicate that there is a reasonable spread of data for most items. Smaller interquartile ranges for variables such as the situation subscale from the cause scale indicate highly consistent responses from parents. 
Table 2

Descriptive statistics for all variables included in the analysis.

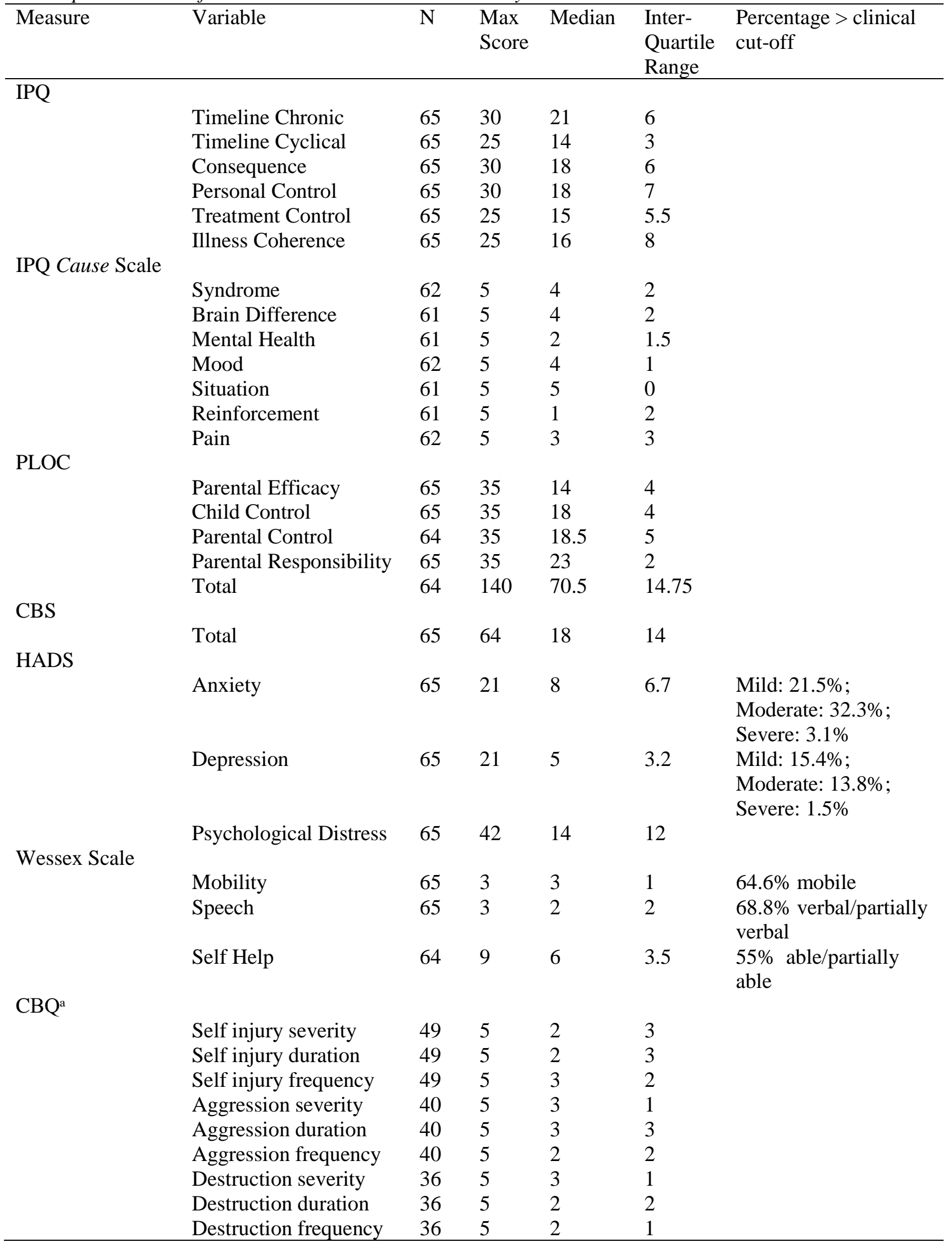


Table 3.

The duration, severity and frequency of challenging behaviour measured by the $C B Q$.

\begin{tabular}{|c|c|c|c|}
\hline & $\begin{array}{l}\text { Self-injurious } \\
\text { behaviour }^{\mathrm{a}}\end{array}$ & Aggression & $\begin{array}{l}\text { Destruction of } \\
\text { Property }\end{array}$ \\
\hline \multicolumn{4}{|l|}{ Presence of behaviour } \\
\hline Yes & $49(75.4 \%)$ & $40(61.5 \%)$ & $36(55.4 \%)$ \\
\hline \multicolumn{4}{|c|}{ Duration (longest episode) } \\
\hline$<$ minute & $16(32.7 \%)$ & $10(25.0 \%)$ & $8(22.2 \%)$ \\
\hline$<5$ minutes & $15(30.6 \%)$ & $10(25.5 \%)$ & $13(36.1 \%)$ \\
\hline$<15$ minutes & $5(10.2 \%)$ & $9(22.5 \%)$ & $4(11.1 \%)$ \\
\hline$<$ hour & $6(12.2 \%)$ & $7(17.5 \%)$ & $5(13.9 \%)$ \\
\hline$>$ hour & $7(14.3 \%)$ & $4(10.0 \%)$ & $6(16.7 \%)$ \\
\hline \multicolumn{4}{|c|}{ Severity (physical contact or } \\
\hline prevention necessary) & $19(38.8 \%)$ & $4(10.0 \%)$ & $6(16.7 \%)$ \\
\hline Never & $8(16.3 \%)$ & $14(35.0 \%)$ & $10(27.8 \%)$ \\
\hline Once month & $9(18.4 \%)$ & $13(32.5 \%)$ & $12(33.3 \%)$ \\
\hline Once week & $10(20.4 \%)$ & $7(17.5 \%)$ & $7(19.4 \%)$ \\
\hline Once day & $3(6.1 \%)$ & $2(5.0 \%)$ & $1(2.8 \%)$ \\
\hline \multicolumn{4}{|l|}{ Once an hour } \\
\hline \multicolumn{4}{|c|}{ Frequency (next predicted incident) } \\
\hline Next month & $10(20.4 \%)$ & $11(27.5 \%)$ & $8(22.2 \%)$ \\
\hline Next week & $13(26.5 \%)$ & $14(35.0 \%)$ & $12(33.3 \%)$ \\
\hline Tomorrow & $15(30.6 \%)$ & $8(20.0 \%)$ & $11(30.6 \%)$ \\
\hline Next hour & $7(14.3 \%)$ & $3(7.5 \%)$ & $3(8.3 \%)$ \\
\hline Next 15 minutes & $4(8.2 \%)$ & $4(10.0 \%)$ & $2(5.6 \%)$ \\
\hline
\end{tabular}

${ }^{\mathrm{a}}$ Hits self against object $=21 \%$; hits self with object $=19.4 \%$; bites self $(29 \%)$, pulls skin $/$ hair $=29 \%$, rubs $/$ scratches $=35.5 \%$, inserts objects into orifices $=19.4 \%$.

The first aim was to document the level of anxiety and depression experienced by parents of adult children with ID who engage in CB. Thirty-seven (56.9\%) parents fell above the cut-off for anxiety, and nineteen (30.8\%) fell above the cut-off for depression on the HADS. These 
scores range from $(46.2 \%-66.7 \%)$ for anxiety across syndrome groups, and $(15.4 \%-50 \%)$ for depression. Due to the high prevalence of mental health difficulties reported in carrier females with FXS (Freund, Reiss, \& Abrams, 1993), analyses were conducted to compare the number of parents of children with FXS $(N=12)$ falling above the cut-off for anxiety and depression in comparison with the remaining participants. No significant differences were found for anxiety and depression, $\chi^{2}=.570, p=.450 ; \chi^{2}=.045, p=.831$.

\section{Associations between parental well-being, behaviours that challenge and parental cognitive variables}

The second aim of this study was to explore associations between parental psychological distress and scores on a measure of $\mathrm{CB}$, and to explore whether parental cognitive variables mediated an association between these variables. The associations between parental cognitive variables, HADS psychological distress index, and CB are shown in Table 4.

Table 4.

Associations between parental perceptions, HADS scores and behaviours that challenge

\begin{tabular}{llr}
\hline & & \multicolumn{2}{c}{$\begin{array}{c}\text { HADS } \\
\text { Personal } \\
\text { Distress }\end{array}$} \\
\hline Parent Cognitive \\
Variables & & .20 \\
& IPQ-R Timeline & -.08 \\
& IPQ-R Timeline Cyclic & .06 \\
& IPQ-R Consequences & -.16 \\
& IPQ-R Personal Control & -.09 \\
& IPQ-R Treatment Control & .23 \\
& IPQ-R Illness Coherence & .01 \\
& Cause scale: Syndrome & .10 \\
& Cause scale: Brain Development & -.06 \\
& Cause scale: Mental Health & .03 \\
& Cause scale: Situation & .03 \\
& Cause scale: Pain & -.09 \\
& Cause scale: Reinforcement & $.38 * *$ \\
\cline { 2 - 3 } Person & PLOC-SFR Total & -.02 \\
\cline { 2 - 3 } Characteristics & CBS Total & .19 \\
\cline { 2 - 3 } & Self-Help Score & .18 \\
& CBQ SIB & .13 \\
& CBQAgg/Des & .04 \\
\hline$* * * p<.005, * * p<.01, * p<.05$ &
\end{tabular}




\section{Associations between parental well-being, behaviours that challenge}

Contrary to predictions, the composite $\mathrm{CB}$ score was not associated with the HADS psychological distress index $(p>.05)$. These findings remained consistent when this analysis was repeated with the SIB composite and the Agg/Des composite, and when the HADS anxiety and HADS depression subscales were examined ( $p s>.05)$.

\section{Associations between parental well-being and parental perceptions}

The only parental cognitive variable that was associated with the HADS psychological distress index was the total score on the PLOC-SFR, $R=.38, p=.002$. Contrary to the hypotheses, none of the IPQ-R subscales were associated with parental psychological distress. These results remained consistent when the analysis was repeated with the HADS anxiety and HADS depression subscales $(p s>.05)$.

\section{Mediation Analysis}

As the PLOC-SFR has four subscales, these subscales were included in a mediation analysis to explore whether locus of control mediated an association between $\mathrm{CB}$ and parental psychological distress. Figure 1 shows the unstandardized beta coefficients and significance values for the mediation analysis. The overall model was significant $\left(R^{2}=.22 ; p=.001\right)$ and accounted for $22 \%$ of the variance in parental psychological distress. The only individual significant mediator of $\mathrm{CB}$ on parental distress was the PLOC-SFR variable, child control over parent's life (Table 5). This analysis was repeated with SIB composite score and Agg/Des composite score as the IVs, but no significant direct or indirect effects were found $(p s>.05)$ 


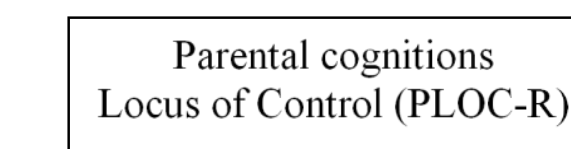

PLOC-R Parental Control Over Child \& CBQ: 1.27

PLOC-R Child Control Over Parent \& CBQ: $1.38^{*}$

PLOC-R Parental Responsibility \& CBQ: 1.27

PLOC-R: Parental Efficacy and CBQ: 1.45*

PLOC-R Parental Control Over Child \& HADS: - -18

PLOC-R Child Control Over Parent \& HADS: .57*

PLOC-R Parental Responsibility \& HADS: .65*

PLOC-R Parental Efficacy \& HADS: -.06

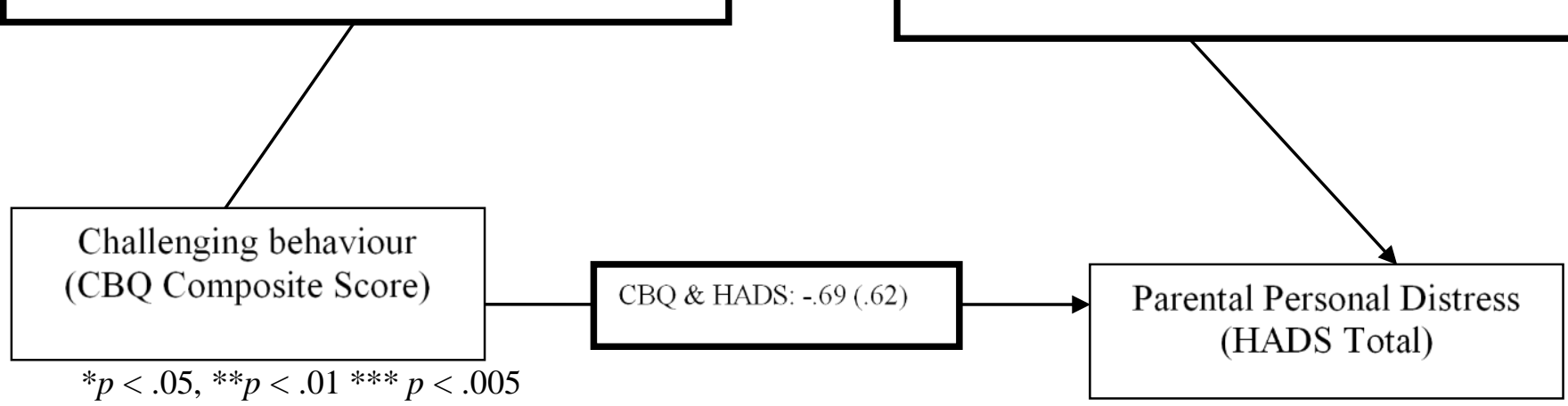

Figure 1. Proposed mediation model for challenging behaviour and parental personal distress.

Unstandardised Beta Coefficients are displayed with significance values.

Table 5

Mediation of the effect of aggression/destruction on parental distress through locus of control

\begin{tabular}{|c|c|c|c|c|}
\hline & Bias & $\begin{array}{l}\text { Standard } \\
\text { Error }\end{array}$ & $\begin{array}{c}\text { Lower BC } \\
95 \% \mathrm{Cl}\end{array}$ & $\begin{array}{c}\text { Upper BC } \\
95 \% \mathrm{Cl}\end{array}$ \\
\hline Parental Efficacy & -.001 & .45 & -.1 .38 & .62 \\
\hline $\begin{array}{l}\text { Parental } \\
\text { Responsibility }\end{array}$ & .06 & .64 & -.11 & 2.37 \\
\hline $\begin{array}{l}\text { Parental Control } \\
\text { over Child }\end{array}$ & -.04 & .40 & -.151 & 0.22 \\
\hline $\begin{array}{l}\text { Child Control over } \\
\text { Parent's Life }\end{array}$ & -.08 & .52 & .11 & 2.53 \\
\hline Total & -.06 & .90 & -.28 & 3.33 \\
\hline
\end{tabular}

\section{Causal Factors Endorsed by Parents on Cause Scale}

A secondary aim of this study was to develop the new cause scale for the IPQ-R and to explore the causal factors for CB that parents endorsed on this subscale. Total CB total score 
(self-injury, aggression, \& destruction) was appropriate for these analyses as no differences were found between those who indicated prior to completing the IPQ-R that self-injury was the behaviour of most concern and those where aggression was of most concern $(p \mathrm{~s}>.05)$. A Friedman test revealed that there was a significant difference between parents' responses across subscales of the cause scale $\left(\chi^{2}(6)=119.17, p<.001\right)$. Results of post hoc tests are depicted in Figure 2.

Parents more frequently agreed that situational factors and atypical brain development underpinned CB (self-injury, aggression, property destruction). They were least likely to agree that the behaviour was reinforced/shaped, related to poor mental health or pain (Figure 2).

Parents more frequently agreed that situational factors and atypical brain development underpinned CB (self-injury, aggression, property destruction). They were least likely to agree that the behaviour was reinforced/shaped, related to poor mental health or pain. 
Table 6.

Causal factors endorsed by parents and associations with broader parental perceptions

\begin{tabular}{lrrrrrr}
\hline & Syndrome & $\begin{array}{r}\text { Brain } \\
\text { Development }\end{array}$ & $\begin{array}{r}\text { Mental } \\
\text { Health }\end{array}$ & $\begin{array}{r}\text { Situational/ } \\
\text { Environmental }\end{array}$ & Reinforcement & Pain \\
\cline { 2 - 7 } IPQ-R Timeline & $.35^{*}$ & .14 & -.08 & -.15 & -.20 & -.06 \\
IPQ-R Timeline Cyclic & .15 & .05 & .14 & .15 & .10 & .20 \\
IPQ-R Consequences & -.01 & -.06 & .06 & -.10 & .06 & .20 \\
IPQ-R Personal Control & -.19 & .14 & .03 & $.30^{*}$ & .14 & .20 \\
IPQ-R Treatment Control & -.18 & -.16 & .23 & .16 & .05 & .18 \\
IPQ-R Illness Coherence & -.16 & $-.30^{*}$ & -.11 & $-.32^{*}$ & -.06 & .00 \\
PLOC-SFR: Total & .20 & .18 & .03 & .03 & .14 & .11 \\
CBS: Total & $-.30^{*}$ & $-.27 *$ &, 05 & & &
\end{tabular}




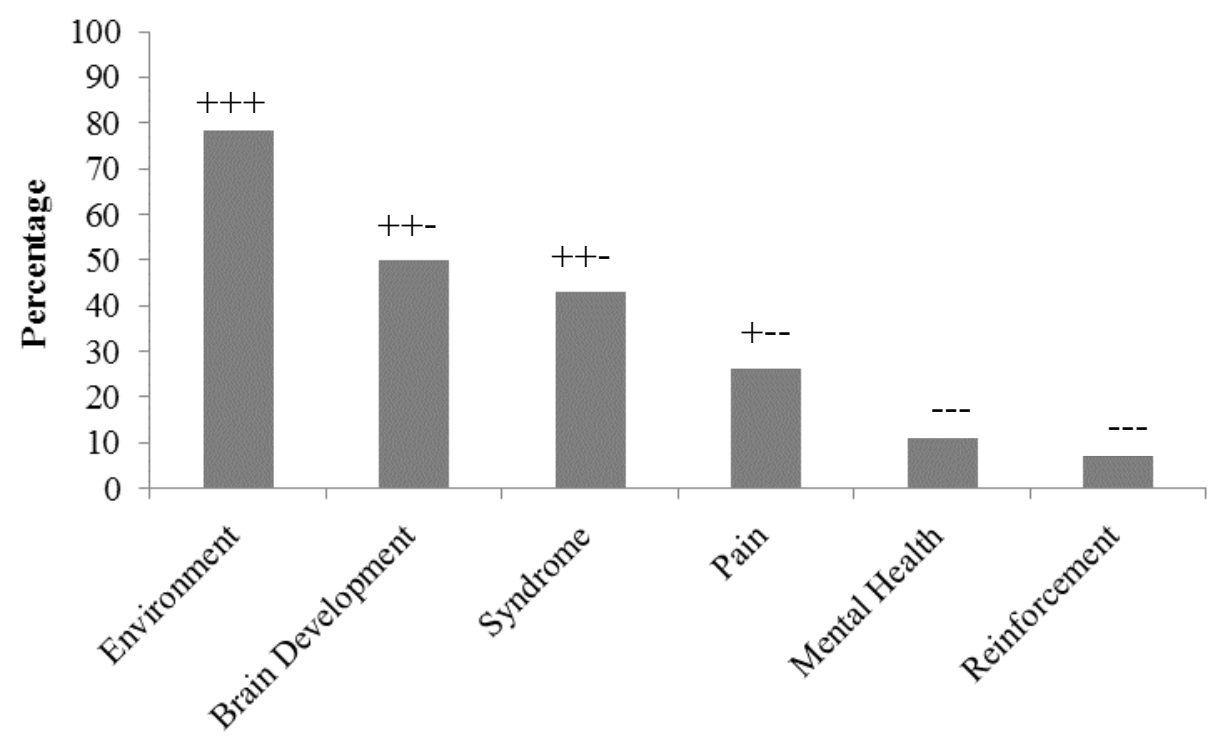

Causal Factor

Figure 2. Percentage of people who agreed with both items from each causal scale.

+ greater than one other causal factor

- less than one other causal factor

Note. Percentage of participants who agreed that causal factor impacted on behaviour (agreed to both items measuring the causal factor). 'Percentage agreed' is displayed to aid interpretation as the mean score could not be presented due to the non-parametric nature of these data and the median score did not capture subtle differences between syndrome and $\mathrm{mood} / \mathrm{brain}$ development items. Statistical analyses were conducted using the total composite score for the cause scale.

As the newly developed cause scale formed part of the IPQ-R patterns of associations between this subscale, other parental cognitive measures were examined as part of an exploratory analysis (Table 6). None of the correlations reached significance at $p<.005$. There were some trends in the data at $p<.01$ and $<.05$; however, due to the likelihood of making a type I error these trends need to be interpreted with caution. For example, there was a positive trend between the belief that reinforcement was a causal factor and a stronger belief in effective treatments/interventions on the IPQ-R. There was a positive trend between a belief that pain and the environment were causal factors and greater personal control on the 
IPQ-R. A trend was also found between endorsing environmental factors and more internal locus of control measured by the PLOC-SFR. There was a trend between the belief that CB was caused by atypical brain development and a lower sense that $\mathrm{CB}$ was a coherent difficulty on the IPQ-R, and a weaker belief that the person with ID had control over CB on the CBS. A greater belief that the child's syndrome caused CB was associated with a stronger belief that the behaviour would last a long time on the IPQ-R and a weaker belief that the person with ID had control over their behaviour on the CBS.

\section{Discussion}

To our knowledge, this is the first study to address parental perceptions regarding adult children with ID showing chronic CB. The primary aims were to describe parental levels of psychological distress, explore the association between psychological distress and degree of $\mathrm{CB}$, and to explore whether parental perceptions mediate this association. It was anticipated that higher scores on a CB measure would be associated with greater parental psychological distress. It was also predicted that beliefs about the timeline of $\mathrm{CB}$ and beliefs about personal control over CB may mediate the association between $\mathrm{CB}$ and parental distress. A secondary aim was to develop a new cause scale for the IPQ-R for CB and document parents' perceptions of the cause of $\mathrm{CB}$.

In terms of global psychological distress, a high proportion of parents reached the cut-off for anxiety (56.9\%) and depression (30.8\%) on the HADS. Heightened anxiety and depression are consistent with previous studies and appear typical for ID populations. For example, White and Hastings (2004) found that in parents of adolescents with severe ID, $61 \%$ fell above the cut-off for anxiety and $36 \%$ for depression on the HADS. Hastings and Brown (2002) also employed the HADS and found a similar profile of mental health difficulties in 
mothers of children with autism and ID (54\% anxiety; 38\% depression). As the current study reports on an older cohort of individuals, it suggests anxiety and depression might be chronic but stable in parents with children with ID, although further longitudinal studies would be needed to confirm this. Importantly, these elevated levels of anxiety and depression appear to be present across syndrome groups included in the sample, which highlights the pervasive nature of these difficulties.

Overall, these findings highlight the vulnerability of older cohorts of parents and the need for evidence-based therapies, such as cognitive behavioural therapy or acceptance and commitment therapies, targeted specifically at these cohorts (Butler, Chapman, Forman, \& Beck, 2006; Zettle, 2015). Referrals to ID services are often focused on difficulties being experienced by the person with ID; however, given the high prevalence rates of anxiety and depression, clinicians should routinely assess the mental health of the primary caregiver. This is important, not only for sign-posting the primary caregiver to adult services or support groups, but also because poor parental mental health is likely to influence how parents respond to the person with ID, which may reduce successful implementation of behavioural interventions for CB (Xu et al., 2014).

Contrary to predictions, degree of $\mathrm{CB}$ was not associated with psychological distress measured by the HADS. This result does not fit with previous research with children with ID that has found a strong association between behavioural difficulties and parental outcomes. Results indicated that parents who perceived that their child exerted greater control over their lives experienced more distress. Despite the absence of a significant association between CB and parental psychological distress, it was found that that these variables were associated through child control over parent's life, which acted as an intervening (or mediator) variable. 
The relationship between child control over parent's life and psychological distress fits with research that highlights the role of parental locus of control in predicting parental distress (Lloyd \& Hastings, 2009) and with the broader literature that indicates a link between locus of control and depression (Benassi, Sweeney, \& Dufour, 1988). There are several reasons why child's control over parent's life may have been found to be a significant mediator in the current study in the absence of a direct association between CB and parental psychological distress. CB may directly influence parental well-being when children are young but over time CB may exert a stronger influence on beliefs about the child's control over the parent than on parental well-being. An alternative explanation is that this finding could be specific to this population of individuals with ID who all have a diagnosis of a genetic syndrome. Many parents indicated that they believed that $\mathrm{CB}$ was caused by their child's brain development or syndrome. Given that the families included in this study all had children with a genetic diagnosis, many parents may believe that there is nothing they can do to reduce behaviour, and thus, their well-being may then be dependent on the control they believe their child has over their life. In addition, the results may have arisen because of the design of the study. For example, there was a small sample size and there may be differential power for detecting these effects, or locus of control may have been measured with more precision than CB.

Targeted interventions that focus on parental locus of control or self-efficacy may be beneficial for reducing anxiety and depression. Studies with typically developing children have shown that parenting training packages can be effective at increasing parental locus of control and self-efficacy (Hood \& Eyberg, 2003; Kaminski, Valle, Filene, \& Boyle, 2008). Parenting groups are often targeted at those with younger children, and while this may be 
effective from an early intervention standpoint, there may be a need for developing targeted groups for those who are supporting and adult with ID.

The secondary aim of this paper was to develop a new cause scale for the adapted IPQ-R for CB. The newly developed cause scale needs further development to explore test-retest reliability and construct validity. While it is important to interpret the correlations with caution, due to the danger of a type I error, an exploratory analysis of intercorrelations between parental perception variables suggests that the scale has face validity. For example, parents who endorsed operant reinforcement as a causal factor were more likely to believe in effective interventions for $\mathrm{CB}$, which is understandable given that operant contingencies can be modified. There was tentative evidence that parents who endorse internal causal factors such as the person's syndrome are more likely to believe their children have less control over behaviour (measured by the CBS), which may suggest a more deterministic view of CB. Similar associations between parent beliefs in a biological cause and lower controllability have been found in ADHD populations without ID (Johnston \& Freeman, 1997).

Very few parents $(<10 \%)$ viewed operant reinforcement as a cause of aggression/selfinjury/destruction, which suggests that most parents may not endorse a functional account of behaviour. Overall, parents tended to endorse situation/environment as the main cause of $\mathrm{CB}$, along with atypical brain development and mood. This result fits with Oliver et al. (1996) who found that carers often endorse biological and emotional causes of behaviour. Given that a high proportion of families endorsed situational factors as underpinning behaviour, it appears families may be more likely to endorse the antecedent aspect of a functional account of behaviour while not linking this with the impact of reinforcement through consequences. 
Low endorsement of reinforcement/learning as a causal factor points towards one of four explanations, which clinicians should be mindful of when working with families: (1) Families have not received information about reinforcement and learning theory, (2) families do not agree with the information they have received about reinforcement due to difficulty implementing strategies or because of lack of appropriate support, (3) families find it difficult to respond to questions about behaviour being reinforced due to feelings of responsibility, and (4) reinforcement is not a direct causal factor in this population and parents' appraisals are accurate. The sample was made up of parents whose children's genetic syndrome is a risk factor for the development of $\mathrm{CB}$, so it is understandable why families may endorse internal biological/genetic factors as being associated with behaviour. In addition, high levels of impulsivity and overactivity are reported in some of these syndrome groups and these characteristics are correlates of behaviour that challenges (Arron et al., 2011). These associations have led to the hypothesis that behavioural dysregulation may be involved in the persistence of behaviour over time (Oliver \& Richards, 2015). If the behavioural dysregulation hypothesis is correct, parents may be accurately appraising the role of biological/genetic factors, rather than their endorsement of this causal factor being an inaccurate perception. The presence of behavioural dysregulation could also partially explain why some parents feel that their child exerts a high level of control over their lives.

Despite the possibility that parents may be accurately appraising internal causes of behaviour, gene-environment interactions are still likely to be very important for determining the development of $\mathrm{CB}$ as not everyone with a genetic syndrome develops $\mathrm{CB}$ (Waite et al., 2014), so parents' low endorsement of operant reinforcement is concerning as it is the dominant model for understanding the development and maintenance of behaviour. Research has indicated that those who endorse internal causes (biological/genetic/mood) are 
more likely to respond to behaviour that challenges in reinforcing ways (Oliver et al., 1996), so parents of children with genetic syndromes may be more likely to become stuck in an unhelpful reinforcement cycle with their children. Further investigation is warranted to understand why families do not endorse learning theory explanations so that more effective intervention packages can be developed. Clinicians working with families should explore families pre-existing beliefs about the causes of behaviour and carefully examine why parents may not endorse an operant reinforcement model. Failure to do this may reduce the quality of the therapeutic alliance and shared understanding of the difficulties parents are facing.

Contrary to initial predictions, no associations were found between the IPQ-R and parent well-being. However, as the adapted IPQ-R has good internal consistency, the measure may have utility for exploring other questions related to adherence to interventions and service receipt as this measure has been used to explore these areas in other populations (Fortune, Richards, Main, \& Griffiths, 2000; Murphy, Dickens, Creed, \& Bernstein, 1999). Understanding how parents construct representations of behaviours may help predict which parents seek support (Cooper, Lloyd, Weinman, \& Jackson, 1999; Heijmans, 1998; Heijmans \& de Ridder, 1998; Moss-Morris, Petrie, \& Weinman, 1996; Scharloo, Kaptein, Weinman, Vermeer, \& Rooijmans, 2000; Scharloo et al., 1998; Weinman, Petrie, Sharpe, \& Walker, 2000).

Limitations of this study include the correlational design, specific focus on adults with genetic syndromes, although this group is at very high risk of CB. Further research could employ longitudinal methodology or a cross-sectional approach that incorporates a younger group so that the parental perceptions can be explored developmentally. A larger sample size would be useful to examine whether these results are consistent across syndrome groups and 
the behaviours included. It would be interesting to compare this group of people with genetic syndromes to a group of individuals with ID without genetic syndromes as diagnosis of a genetic syndrome may be contributing to specific attributions about behaviour. This is particularly important as CB may present differently across syndromes (e.g., skin picking in PWS) and a larger sample would allow for a more nuanced approach to analysis.

A further study exploring parental perceptions of $\mathrm{CB}$ and well-being should gather more information on the adults with ID and their parents, including in-depth information on adaptive abilities and communication skills. It will also be important to explore the type of support that families receive and how this may be associated with parental outcomes. A larger sample would facilitate an analysis comparing parents of younger adults who are at school/college to individuals who are at home for a greater proportion of time, as their level of support may differ. The absence of information on support may be another explanation for why an association was not found between challenging behaviour and parental mental health, particularly given that support has been shown to mediate this association (White \& Hastings, 2004). Despite this, this study has been important for highlighting potential factors associated with psychological distress in an older cohort of parents that may be shared across these groups, for example locus of control.

Alteration to the IPQ-R may have changed the psychometric properties of the measure so further validation is needed in ID populations. However, the newly developed cause scale appears particularly promising, and all measures employed had good face validity. Despite measures having face validity, some of the significant correlations reported in this study may have been due to items overlapping across measures. Example items from key subscales are presented in Appendix B. Some items on the PLOC-SFR ask about a child's impact on the parent's independence, which may overlap with items on the HADS that ask parents to 
indicate whether they 'still enjoy the things that they used to'. However, unlike the HADS, all questions on the PLOC-SFR are parenting orientated, and if the HADS and PLOC-SFR were measuring the same construct, $\mathrm{CB}$ might have been expected to be associated with both measures, rather than just the PLOC-SFR. There were several associations between the newly developed cause subscale (Appendix A) and the IPQ-R. The cause subscale asks about explicit causes of CB such as physical pain, mood, and mental health, whereas none of the other subscales of the IPQ-R assess this. However, due to the number of parental variables measured as part of this study, some overlap between items cannot be completely ruled out, which is a limitation of the study.

A final limitation is that the results are only generalizable to mothers because a high proportion of the participants were female. Previous research has shown differences between fathers and mothers, and if a higher proportion of the sample had been fathers, it would have been possible to explore this statistically (Hastings \& Brown, 2002; Hastingset al., 2005).

Overall, this study found that there were high levels of psychological distress in parents of adults with chronic CB. Parental locus of control was associated with parental psychological distress in this population rather than the degree of $\mathrm{CB}$ exhibited by the individual with ID. Further research is needed to understand parents' causal attributions about behaviour when their child has a rare genetic syndrome.

\section{Conflict of Interest}

The authors have no conflict of interest. 


\section{References}

Al Anbar, N. N., Dardennes, R. M., Prado-Netto, A., Kaye, K., \& Contejean, Y. (2010).

Treatment choices in autism spectrum disorder: The role of parental illness perceptions.

Research in Developmental Disabilities, 31(3), 817-828. DOI: 10.1016/j.ridd.2010.02.007

Arron, K., Oliver, C., Berg, K., Moss, J., \& Burbidge, C. (2011). Delineation of behavioural phenotypes in genetic syndromes. Prevalence, phenomenology and correlates of selfinjurious and aggressive behaviour. Journal of Intellectual Disability Research, 55(2), 109120. DOI: $\underline{10.1111 / \mathrm{j} .1365-2788.2010 .01337 . \mathrm{x}}$

Baron, R. M., \& Kenny, D. A. (1986). The moderator-mediator variable distinction in social psychological research: Conceptual, strategic, and statistical considerations. Journal of personality and social psychology, 51(6), 1173.

Barrowclough, C., Lobban, F., Hatton, C., \& Quinn, J. (2001). An investigation of models of illness in carers of schizophrenia patients using the Illness Perception Questionnaire. British Journal of Clinical Psychology, 40(4), 371-385. DOI: 10.1348/014466501163869

Beail, N. (2003). What works for people with mental retardation? Critical commentary on cognitive-behavioral and psychodynamic psychotherapy research. Mental Retardataion, 41(6), 468-472. DOI: 10.1352/0047-6765(2003)41<468:WWFPWM>2.0.CO;2

Beck, A., Hastings, R. P., Daley, D., \& Stevenson, J. (2004). Pro-social behaviour and behaviour problems independently predict maternal stress. Journal of Intellectual and Developmental Disability, 29(4), 339-349. DOI: 10.1080/13668250400014509

Bjelland, I., Dahl, A. A., Haug, T. T., \& Neckelmann, D. (2002). The validity of the Hospital Anxiety and Depression Scale-An updated literature review. Journal of Psychosomatic Research, 52(2), 69-78. DOI: 10.1016/S0022-3999(01)00296-3

Breau, L. M., Camfield, C. S., McGrath, P. J., \& Finley, G. A. (2003). The incidence of pain in children with severe cognitive impairments. Archives of Pediatrics \& Adolescent Medicine, 157(12), 1219. DOI: $\underline{\text { 10.1001/archpedi.157.12.1219 }}$ 
Benassi, V. A., Sweeney, P. D., \& Dufour, C. L. (1988). Is there a relation between locus of control orientation and depression?. Journal of abnormal psychology, 97(3), 357. DOI: 10.1037/0021-843X.97.3.357

Butler, A. C., Chapman, J. E., Forman, E. M., \& Beck, A. T. (2006). The empirical status of cognitive-behavioral therapy: a review of meta-analyses. Clinical psychology review, 26(1), 17-31.

Campis, L. K., Lyman, R. D., \& Prentice-Dunn, S. (1986). The parental locus of control scale: Development and validation. Journal of Clinical Child Psychology, 15(3), 260-267. DOI: $\underline{10.1207 / \mathrm{s} 15374424 \mathrm{jccp} 1503 \_10}$

Cooper, A., Lloyd, G.S., Weinman, J. and Jackson, G. (1999). Why patients do not attend cardiac rehabilitation: Role of intentions and illness beliefs. Heart, 82(2), 234-236. DOI: $10.1136 / \mathrm{hrt} .82 .2 .234$

Dagnan, D., Grant, F., \& McDonnell, A. (2004). Understanding challenging behaviour in older people; the development of the Controllability Beliefs Scale. Behavioural and Cognitive Psychotherapy, 32(4), 501-506. DOI: $\underline{\text { 10.1017/S1352465804001675 }}$

Department of Health (2001). Valuing People: a new strategy for learning disability for the 21st century a white paper. London: Department of Health.

Dilworth, J. A., Phillips, N., \& Rose, J. (2011). Factors relating to staff attributions of control over challenging behaviour. Journal of Applied Research in Intellectual Disabilities, 24(1), 29-38. DOI: $10.1111 / \mathrm{j} .1468-3148.2010 .00570 . x$

Eisenhower, A. S., Baker, B. L., \& Blacher, J. (2005). Preschool children with intellectual disability: syndrome specificity, behaviour problems, and maternal well-being. Journal of Intellectual Disability Research, 49(9), 657-671. DOI: 10.1111/j.1365-2788.2005.00699.x 
Emerson, E., Kiernan, C., Alborz, A., Reeves, D., Mason, H., Swarbrick, R., ... \& Hatton, C. (2001). The prevalence of challenging behaviors: A total population study. Research in developmental disabilities, 22(1), 77-93. DOI: 10.1016/S0891-4222(00)00061-5

Esbensen, A. J. (2011). Families of individuals with intellectual disability and comorbid mental health problems. Journal of Mental Health Research in Intellectual Disabilities, 4(3), 140157. DOI: $\underline{10.1080 / 19315864.2011 .597018}$

Freund, L. S., Reiss, A. L., \& Abrams, M. T. (1993). Psychiatric disorders associated with fragile $\mathrm{X}$ in the young female. Pediatrics, 91(2), 321-329.

Fritz, M. S., \& MacKinnon, D. P. (2007). Required sample size to detect the mediated effect. Psychological science, 18(3), 233-239.

Fortune, D. G., Richards, H. L., Main, C. J., \& Griffiths, C. E. (2000). Pathological worrying, illness perceptions and disease severity in patients with psoriasis. British Journal of Health Psychology, 5(1), 71-82. DOI: $\underline{\text { 10.1348/135910700168775 }}$

Hagger, M. S., \& Orbell, S. (2003). A meta-analytic review of the common-sense model of illness representations. Psychology and Health, 18(2), 141-184. DOI:

$\underline{10.1080 / 088704403100081321}$

Hassall, R., Rose, J., \& McDonald, J. (2005). Parenting stress in mothers of children with an intellectual disability: The effects of parental cognitions in relation to child characteristics and family support. Journal of Intellectual Disability Research, 49(6), 405-418. DOI: 10.1111/j.1365-2788.2005.00673.x

Hastings, R. P. (2002). Parental stress and behaviour problems of children with developmental disability. Journal of Intellectual and Developmental Disability, 27(3), 149-160. DOI: $\underline{10.1080 / 1366825021000008657}$

Hastings, R. P., \& Brown, T. (2002). Behavior problems of children with autism, parental selfefficacy, and mental health. American Journal of Mental Retardation, 107(3), 222-232. DOI: 10.1352/0895-8017(2002)107<0222:BPOCWA>2.0.CO;2 
Hastings, R. P., Kovshoff, H., Ward, N. J., Degli Espinosa, F., Brown, T., \& Remington, B. (2005). Systems analysis of stress and positive perceptions in mothers and fathers of preschool children with autism. Journal of autism and developmental disorders, 35(5), 635-644. DOI: $10.1007 / \mathrm{s} 10803-005-0007-8$

Heijmans, M. (1998). Coping and adaptive outcome in chronic fatigue syndrome: importance of illness cognitions. Journal of Psychosomatic Research, 45(1), 39-51. DOI: 10.1016/S00223999(97)00265-1

Heijmans, M. and de Ridder, D. (1998). Assessing illness representations of chronic illness: Explorations of their disease-specific nature. Journal of Behavioral Medicine, 21(5), 485503. DOI: $\underline{10.1023 / \mathrm{A}: 1018788427100}$

Hill, C., \& Rose, J. (2009). Parenting stress in mothers of adults with an intellectual disability: Parental cognitions in relation to child characteristics and family support. Journal of Intellectual Disability Research, 53(12), 969-980. DOI: 10.1111/j.1365-2788.2009.01207.x

Hill, C., \& Rose, J. (2010). Parenting stress models and their application to parents of adults with intellectual disabilities. The British Journal of Development Disabilities, 56(110), 19-37. DOI: $\underline{10.1179 / 096979510799103023}$

Hodapp, R. M., Fidler, D. J., \& Smith, A. C. M. (1998). Stress and coping in families of children with Smith-Magenis syndrome. Journal of Intellectual Disability Research, 42(5), 331-340. DOI: $\underline{10.1046 / j .1365-2788.1998 .00148 . x}$

Hood, Korey K., and Sheila M. Eyberg. "Outcomes of Parent-Child Interaction Therapy: Mothers' reports of maintenance three to six years after treatment." Journal of Clinical Child and Adolescent Psychology 32, no. 3 (2003): 419-429.

Hyman, P., Oliver, C., \& Hall, S. (2002). Self-injurious behavior, self-restraint, and compulsive behaviors in Cornelia de Lange syndrome, American Journal of Mental Retardation, 107(2), 146-154. DOI: 10.1352/0895-8017(2002)107<0146:SIBSRA>2.0.CO;2 
Iwata, B. A., Dorsey, M. F., Slifer, K. J., Bauman, K. E., \& Richman, G. S. (1994). Toward a functional analysis of self-injury. Journal of Applied Behavior Analysis, 27(2), 197-209. DOI: $\underline{10.1901 / j a b a .1994 .27-197}$

Johnston, C., \& Freeman, W. (1997). Attributions for child behavior in parents of children without behavior disorders and children with attention deficit-hyperactivity disorder. Journal of Consulting and Clinical Psychology, 65(4), 636. DOI: 10.1037/0022-006X.65.4.636

Johnston, M., Pollard, B., \& Hennessey, P. (2000). Construct validation of the hospital anxiety and depression scale with clinical populations. Journal of Psychosomatic Research, 48(6), 579-584, DOI: 10.1016/S0022-3999(00)00102-1

Jones, L., Hastings, R. P., Totsika, V., Keane, L., \& Rhule, N. (2014). Child behavior problems and parental well-being in families of children with autism: the mediating role of mindfulness and acceptance. American journal on intellectual and developmental disabilities, 119(2), 171-185.

Kalsy, S., Heath, R., Adams, D., \& Oliver, C. (2007). Effects of training on controllability attributions of behavioural excesses and deficits shown by adults with Down syndrome and dementia. Journal of Applied Research in Intellectual Disabilities, 20(1), 64-68. DOI: 10.1111/j.1468-3148.2006.00341.x

Kushlick, A., Blunden, R., \& Cox, G. (1973). A method of rating behaviour characteristics for use in large scale surveys of mental handicap. Psychological Medicine, 3(04), 466-478. DOI: $\underline{10.1017 / \mathrm{S} 0033291700054271}$

Lancaster, R. L., Balling, K., Hastings, R., \& Lloyd, T. J. (2013). Attributions, criticism and warmth in mothers of children with intellectual disability and challenging behaviour: a pilot study. Journal of Intellectual Disability Research, DOI: 10.1111/jir.12029

Leventhal, H., Benyamini, Y., Brownlee, S., Diefenbach, M., Leventhal, E., Patrick-Miller, L. \& Robitaille, C. (1997). Illness representations: Theoretical foundations. In: K. J. Petrie, \& J. Weinman (Eds.), Perceptions of health and illness: Current research and applications (pp. 19-45). Amsterdam: Harwood Academic Publishers. 
Leventhal, H., Nerenz, D.R. \& Steele, D.S. (1984). Illness representations and coping with health threats. In: A. Baum, S. E. Taylor, \& J. E. Singer (Eds.), Handbook of psychology and health: Vol. 4. (pp. 219-252). Hillsdale, NJ: Erlbaum.

Lloyd, T., \& Hastings, R. P. (2009). Parental locus of control and psychological well-being in mothers of children with intellectual disability. Journal of Intellectual and Developmental Disability, 34(2), 104-115. DOI: 10.1080/13668250902862074

MacDonald, E. E., Hastings, R. P., \& Fitzsimons, E. (2010). Psychological acceptance mediates the impact of the behaviour problems of children with intellectual disability on fathers' psychological adjustment. Journal of Applied Research in Intellectual Disabilities, 23(1), 27 37. 10.1111/j.1468-3148.2009.00546.x

McClintock, K., Hall, S., \& Oliver, C. (2003). Risk markers associated with challenging behaviours in people with intellectual disabilities: A meta-analytic study. Journal of Intellectual Disability Research, 47(6), 405-416. DOI: 10.1046/j.1365-2788.2003.00517.x

McGill, P., \& Langthorne, P. (2011). Gene-environment interactions and the functional analysis of challenging behaviour in children with intellectual and developmental disabilities. Behavioral Development Bulletin, 11(1), 20-25. DOI: 10.1037/h0100598

Mills, S., \& Rose, J. (2011). The relationship between challenging behaviour, burnout and cognitive variables in staff working with people who have intellectual disabilities. Journal of Intellectual Disability Research, 55(9), 844-857. DOI: 10.1111/j.1365-2788.2011.01438.x

Moss-Morris, R., Petrie, K. J., \& Weinman, J. (1996). Functioning in chronic fatigue syndrome: Do illness perceptions play a regulatory role?. British Journal of Health Psychology, 1(1), 15-

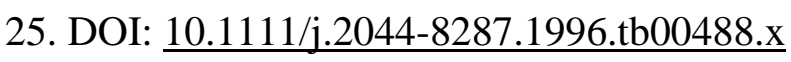

Moss-Morris, R., Weinman, J., Petrie, K., Horne, R., Cameron, L., \& Buick, D. (2002). The revised illness perception questionnaire (IPQ-R). Psychology and Health, 17(1), 1-16. DOI: $\underline{10.1080 / 08870440290001494}$ 
Murphy, G. H., Beadle-Brown, J., Wing, L., Gould, J., Shah, A., \& Holmes, N. (2005). Chronicity of challenging behaviours in people with severe intellectual disabilities and/or autism: A total population sample. Journal of Autism and Developmental Disorders, 35(4), 405-418. DOI: 10.1007/s10803-005-5030-2. DOI: 10.1007/s10803-005-5030-2

Murphy, H., Dickens, C., Creed, F., \& Bernstein, R. (1999). Depression, illness perception and coping in rheumatoid arthritis. Journal of Psychosomatic Research, 46(2), 155-164. DOI: $\underline{10.1016 / \mathrm{S} 0022-3999(98) 00073-7}$

Oliver, C., Hall, S., Hales, J., \& Head, D. (1996). Self-injurious Behaviour and People with Intellectual Disabilities: Assessing the Behavioural Knowledge and Causal Explanations of Care Staff. Journal of Applied Research in Intellectual Disabilities, 9(3), 229-239. DOI: 10.1111/j.1468-3148.1996.tb00112.x

Oliver, C., \& Richards, C. (2015). Practitioner Review: Self-injurious behaviour in children with developmental delay. Journal of Child Psychology and Psychiatry. DOI: 10.1111/jcpp.12425

Oliver, C., Sloneem, J., Hall, S., \& Arron, K. (2009). Self-injurious behaviour in Cornelia de Lange syndrome: 1. Prevalence and phenomenology. Journal of Intellectual Disability Research, 53(7), 575-589. DOI: 10.1111/j.1365-2788.2009.01179.x

Plant, K. M., \& Sanders, M. R. (2007). Predictors of care-giver stress in families of preschool-aged children with developmental disabilities. Journal of Intellectual Disability Research, 51(2), 109-124. DOI: 10.1111/j.1365-2788.2006.00829.x

Preacher, K. J., \& Hayes, A. F. (2008). Asymptotic and resampling strategies for assessing and comparing indirect effects in multiple mediator models. Behavior research methods, 40(3), 879-891.

Quine, L., \& Rutter, D. R. (1994). First diagnosis of severe mental and physical disability: a study of doctor-parent communication. Journal of Child Psychology and Psychiatry, 35(7), 12731287. DOI: $\underline{10.1111 / \mathrm{j} .1469-7610.1994 . t b 01234 . \mathrm{x}}$ 
Rucker, D. D., Preacher, K. J., Tormala, Z. L., \& Petty, R. E. (2011). Mediation analysis in social psychology: Current practices and new recommendations. Social and Personality Psychology Compass, 5(6), 359-371.

Scharloo, M., Kaptein, A.A., Weinman, J., Hazes, J.M., Willems, L.N.A., Bergman, W. and Rooijmans, H.G.M. (1998). Illness perceptions, coping and functioning in patients with rheumatoid arthritis, chronic obstructive pulmonary disease and psoriasis. Journal of Psychosomatic Research, 44(5), 573-585. DOI: 10.1016/S0022-3999(97)00254-7

Scharloo, M., Kaptein, A.A., Weinman, J., Vermeer, B.J. and Rooijmans, H.G.M. (2000). Patients' illness perceptions and coping as predictors of functional status in psoriasis: a 1year follow up. British Journal of Dermatology, 142(5), 899-907. DOI: 10.1046/j.1365$\underline{2133.2000 .03469 . x}$

Taylor, L., Oliver, C. and Murphy, G. (2011). The chronicity of self-injurious behaviour: A longterm follow-up of a total population study. Journal of Applied Research in Intellectual Disability, 25(2), 107-117. DOI: 10.1111/j.1468-3148.2010.00579.x

Totsika, V., Hastings, R. P., Emerson, E., Berridge, D. M., \& Lancaster, G. A. (2011). Behavior problems at 5 years of age and maternal mental health in autism and intellectual disability. Journal of abnormal child psychology, 39(8), 1137-1147.

Weinman, J., Petrie, K.J., Sharpe, N. and Walker, S. (2000). Causal attributions in patients and spouses following first-time myocardial infarction and subsequent lifestyle changes. British Journal of Health Psychology, 5(3), 263-273. DOI: 10.1348/135910700168900

Williams, R. J., \& Rose, J. L. (2007). The development of a questionnaire to assess the perceptions of care staff towards people with intellectual disabilities who display challenging behaviour. Journal of Intellectual Disabilities, 11(2), 197-211. DOI: $10.1177 / 1744629507076932$

White, N., \& Hastings, R. P. (2004). Social and professional support for parents of adolescents with severe intellectual disabilities. Journal of Applied Research in Intellectual Disabilities, 17(3), 181-190.

Xu, Y., Neece, C. L., \& Parker, K. H. (2014). Parental Depression and Child Behavior Problems: 
A Pilot Study Examining Pathways of Influence. Journal of Mental Health Research in Intellectual Disabilities, 7(2), 126-142.

Zettle, R. D. (2015). Acceptance and Commitment Therapy for depression. Current Opinion in Psychology, 2, 65-69.

Zigmond, A. S., \& Snaith, R. P. (1983). The hospital anxiety and depression scale. Acta Psychiatrica Scandinavica, 67(6), 361-370. DOI: 10.1111/j.1600-0447.1983.tb09716 
Appendix A - Cause Scale

\begin{tabular}{|c|c|c|c|c|c|}
\hline & $\begin{array}{l}\text { Strongly } \\
\text { Disagree }\end{array}$ & Disagree & $\begin{array}{l}\text { Neither Agree } \\
\text { or Disagree }\end{array}$ & Agree & Strongly Agree \\
\hline $\begin{array}{l}\text { 1. Poor mental health can explain the } \\
\text { challenging behaviour }\end{array}$ & & & & & \\
\hline $\begin{array}{l}\text { 2. My child engages in the challenging } \\
\text { behaviour because his/her brain works in a } \\
\text { different way }\end{array}$ & & & & & \\
\hline $\begin{array}{l}\text { 3. The challenging behaviour is something } \\
\text { that has been taught unintentionally }\end{array}$ & & & & & \\
\hline $\begin{array}{l}\text { 4. Sometimes my child displays the } \\
\text { challenging behaviour, sometimes they don't } \\
\text { - it depends on what's happening at the time }\end{array}$ & & & & & \\
\hline $\begin{array}{l}\text { 5. Physical pain can explain the challenging } \\
\text { behaviour }\end{array}$ & & & & & \\
\hline $\begin{array}{l}\text { 6. Improving my child's mental health would } \\
\text { reduce the challenging behaviour }\end{array}$ & & & & & \\
\hline $\begin{array}{l}\text { 7. The challenging behaviour is an inevitable } \\
\text { when someone has my child's } \\
\text { syndrome/disorder }\end{array}$ & & & & & \\
\hline $\begin{array}{l}\text { 8. The challenging behaviour is something my } \\
\text { child has learnt to do over time }\end{array}$ & & & & & \\
\hline $\begin{array}{l}\text { 9. The challenging behaviour depends on } \\
\text { whatever mood my child is in }\end{array}$ & & & & & \\
\hline $\begin{array}{l}\text { 10. Reducing pain and discomfort would } \\
\text { reduce the challenging behaviour }\end{array}$ & & & & & \\
\hline $\begin{array}{l}\text { 11. The challenging behaviour is caused by } \\
\text { abnormal brain development }\end{array}$ & & & & & \\
\hline $\begin{array}{l}\text { 12. My child's syndrome/disorder and the } \\
\text { challenging behaviour go hand in hand }\end{array}$ & & & & & \\
\hline $\begin{array}{l}\text { 13. The challenging behaviour may vary } \\
\text { across situations depending on the people or } \\
\text { activities that my child experiences }\end{array}$ & & & & & \\
\hline $\begin{array}{l}\text { 14. My child's emotional state is directly } \\
\text { linked to the challenging behaviour }\end{array}$ & & & & & \\
\hline
\end{tabular}

Situational/Environmental subscale $=$ items $4 \& 13$; Brain development subscale $=2 \& 11$; Mood subscale $=$ items $9 \& 14$; Syndrome subscale items $=7 \& 12$; Pain subscale $=$ items $5 \& 10$; Mental health subscale $=$ items $1 \& 6$; Reinforcement subscale $=$ items $3 \& 8$ 


\section{Appendix B}

Example Items from parental measures (PLOC-SFR, IPQ, CBS \& HADS)

Parental Locus of Control Scale - Revised (PLOC-SFR)

\section{Child Control Over} Parent's Life

Hospital Anxiety and Depression Scale (HADS)

Anxiety

Depression

NA

Illness Perception

Questionnaire

Controllability Beliefs

Scale

My life is chiefly controlled by my child.

My child influences the number of friends I have.

I feel like what happens in my life is mostly determined by my child.

I feel tense or 'wound up'.

I get a sort of frightened feeling as if something awful. is about to happen.

Worrying thoughts go through my mind.

I still enjoy the things I used to enjoy.

I can laugh and see the funny side of things.

I feel cheerful.

Timeline (chronic)

Personal Control

Treatment Control

Illness Coherence
They are trying to wind me up. They can't help themselves.

They are doing it deliberately.

Looking ahead to the future the [insert behaviour] will last a short time.

The [insert behaviour] is likely to be permanent rather than temporary.

Looking ahead to the future the [insert behaviour] will last a long time.

There is a lot I can do to control the [insert behaviour]. What I do determines with the [insert behaviour] gets better or worse.

The future of the [insert behaviour] depends on me.

There is little that can be done to improve the [insert behaviour]. The negative effects of the [insert behaviour] can be avoided with treatment/interventions.

There are effective treatments/interventions that will permanently stop the [insert behaviour].

The [insert behaviour] is puzzling to me.

The [insert behaviour] doesn't make any sense to me.

I don't understand the [insert behaviour].

Note. Items from the child's control over parent's life subscale are given due to it being the only significant mediator. Only subscales of the IPQ-R that showed trends with the Cause subscale are included above.

Note. The complete Cause subscale is included in Appendix A. 